\title{
Identification of mosquito repellent odours from Ocimum forskolei
}

Teun Dekker $^{1 *}$, Rickard Ignell ${ }^{1}$, Maedot Ghebru², Robert Glinwood ${ }^{3}$ and Richard Hopkins ${ }^{3}$

\begin{abstract}
Background: Native mosquito repellent plants have a good potential for integrated mosquito control in local settings. Ocimum forskolei, Lamiaceae, is used in Eritrea as a spatial mosquito repellent inside houses, either through crushing fresh plants or burning dry plants. We verified whether active repellent compounds could be identified using gas-chromatography coupled electroantennogram recordings (GC-EAD) with headspace extracts of crushed plants.

Results: EAD active compounds included (R)-(-)-linalool, (S)-(+)-1-octen-3-ol, trans-caryophyllene, naphthalene, methyl salicylate, (R)-(-)- $\alpha$-copaene, methyl cinnamate and (E)-ocimene. Of these compounds (R)-(-)-linalool, methyl cinnamate and methyl salicylate reduced landing of female Aedes aegypti on human skin-odor baited tubes. The latter two are novel mosquito repellent compounds.

Conclusions: The identification of mosquito repellent compounds contributes to deciphering the mechanisms underlying repulsion, supporting the rational design of novel repellents. The three mosquito repellent compounds identified in this study are structurally dissimilar, which may indicate involvement of different sensory neurons in repulsion. Repulsion may well be enhanced through combining different repellent plants (or their synthetic mimics), and can be a locally sustainable part in mosquito control efforts.
\end{abstract}

Keywords: Ocimum forskolei, Lamiaceae, GC-EAD, Aedes aegypti, mosquito, repellent, linalool, methyl cinnamate, methyl salicylate

\section{Background}

For blood feeding insects, olfaction is the principal sensory modality used in host recognition and location. This is especially true for disease vector mosquitoes, many species of which locate their vertebrate hosts during scotophase [1]. Despite much research, mosquitoes remain a huge burden on society, both as nuisance pests and as vectors of disease. Tropical regions are particularly affected, largely due to the economic and logistical problems associated with conventional control methods, such as insecticide sprays. Although early efforts to control vectors with insecticides were highly effective, their reliance on spraying inside houses to kill resting females has raised environmental and public health concerns [2]. In addition, the contrasting behaviour of different mosquito vector species leads to variation in the effectiveness of different methods

\footnotetext{
* Correspondence: teun.dekker@slu.se

'Division of Chemical Ecology, Department of Crop Science, Swedish

University of Agricultural Sciences PO 44, Alnarp, SE-23053 Sweden

Full list of author information is available at the end of the article
}

in controlling local mosquito populations [e.g., [3]]. Hence, there is a need for integrated sets of control methods adapted to local settings, which can be provided at minimal cost and are thus accessible to local people. One such key method may be the use of locally available plants, traditionally used to deter mosquitoes [4].

Synthetic repellents, such as DEET (N, N, diethyl-toulamide), are commonly used for personal protection from nuisance biting and may also reduce disease transmission if they reduce biting sufficiently [5]. However, synthetic repellents are often too expensive for people living in rural areas in the tropics. As an alternative, the use of plants as insect repellents dates back more than 2000 years [6], and a wide range of plants have been used to repel mosquitoes [7]. These plants may be effective when burnt to produce smoke [e.g., [8,9]], or placed as potted plants inside houses [e.g., [10]]. Ocimum spp. have been documented as traditional repellent plants, and are effective against mosquitoes [9,11-15], black flies [16] and ticks [17]. Ocimum forskolei is used as a
Ciomed Central

() 2011 Dekker et al; licensee BioMed Central Ltd. This is an Open Access article distributed under the terms of the Creative Commons Attribution License (http://creativecommons.org/licenses/by/2.0), which permits unrestricted use, distribution, and reproduction in any medium, provided the original work is properly cited. 
mosquito repellent in the Western lowlands of Eritrea where it grows widely in bush land at an altitude of 100-1000 m. In field studies, O. forskolei hung at the head and foot of the bed in houses, reduced Anopheles arabiensis mosquitoes bites by 53\% [14]. Furthermore, laboratory wind tunnel studies found that when crushed O. forskolei was added to human odour, it became less attractive than human or goat odour alone [18].

Improved knowledge of the volatile compounds released by $O$. forskolei may improve the use of the plant in field situations. It may also lead to the identification of novel compounds with potential for development as synthetic repellents, as well as deciphering the olfactory mechanisms underlying repulsion. The specific questions addressed in this study are: 1) what are the principal components of the volatile odour of crushed O. forskolei that are detected by mosquitoes, and 2) are any of these compounds released by $O$. forskolei involved in repelling Aedes aegypti?

\section{Methods}

\section{Colony}

Aedes aegypti Rockefeller strain were used in all experiments (eggs courtesy of Dr. W. Takken, Wageningen University, The Netherlands). Mosquitoes were reared at $25^{\circ} \mathrm{C}, 80 \% \mathrm{RH}$ and a L:D cycle of $12: 12$ hours without an artificial dusk period. Larvae were reared on Tetra$\left.\min ^{(}\right)$fish food. Pupae were collected into bowls and placed in cages for adults to emerge; males and females were allowed to mate. Adults were kept in cylindrical cages of $20 \mathrm{~cm}$ (diameter) by $30 \mathrm{~cm}$ (height), and provided with a $6 \%$ glucose solution. Females were offered a human arm for blood feeding.

\section{Collection of volatiles from 0 . forskolei}

Plant material was entrained inside glass bell jars (4 1 capacity), resting on circular aluminium plates $(210 \mathrm{~mm}$ diameter $\times 3 \mathrm{~mm}$ thick). The neck opening was sealed with a stopper made from inert silicone rubber containing three holes of $6 \mathrm{~mm}$ diameter for the absorbent tube, air inlet line, and one open hole. Prior to volatile collection, the bell jars were washed with detergent, rinsed with acetone and distilled water and baked overnight (15 hours) at $200^{\circ} \mathrm{C}$. The aluminium plates were washed with detergent and baked overnight (15 hours) at $200^{\circ} \mathrm{C}$. Collected volatiles were absorbed on Porapak Q (60 mg, 80-100 mesh) contained in glass GC inlet liners ( $80 \mathrm{~mm} \times 3 \mathrm{~mm}$ ID, ATAS GL, Netherlands), held in place with glass wool plugs. Prior to volatile collection, Porapak tubes were washed with freshly redistilled diethyl ether and conditioned by heating overnight (15 hours) at $200^{\circ} \mathrm{C}$ under a stream of nitrogen. Air for the entrainment was purified by passing it through molecular sieve (10 $\AA$ ) and activated charcoal traps (10-
18 mesh) before entering the bell jars. Filters were baked overnight at $200^{\circ} \mathrm{C}$ under a stream of nitrogen.

Collections were performed in a controlled environment chamber, at $21 \pm 1^{\circ} \mathrm{C}, 60 \% \mathrm{RH}$, and constant lighting. O. forskolei (18 g stem and leaves removed from four-month old plants) was crushed by hand in the typical manner used in Eritrean homes, and was placed inside the bell jar at around 9 am (3 hours into the photoperiod). Air was pumped into the jar, through the filters, at a rate of $1200 \mathrm{ml} / \mathrm{min}$ for 1 hour to disperse contaminated air, after which the absorbent tube was introduced and air drawn through the absorbent at a rate of $700 \mathrm{ml} / \mathrm{min}$. The vessel was therefore under positive pressure, and the remaining $500 \mathrm{ml} / \mathrm{min}$ air was vented through the extra hole in the silicone stopper. Collections were made for 2 hours. Collected volatiles were eluted from the Porapak Q with $750 \mu$ freshly redistilled diethyl ether and stored at $-20^{\circ} \mathrm{C}$. Prior to GC-EAD and GC-MS, samples were concentrated under a gentle stream of nitrogen to $10 \%$ of their original volume.

\section{GC, GC-EAD, GC-MS}

A Hewlett Packard HP6890 gas chromatograph (GC, Santa Clara, Ca) was fitted with a $30 \mathrm{~m} \times 0.25 \mathrm{~mm}$ ID Solgelwax column (SGE, $30 \mathrm{~m} \times 0.25 \mathrm{~mm}$ i.d., $0.25 \mu \mathrm{m}$ stationary phase, Agilent Santa Clara, Ca), which has superior separation capabilities for polar compounds. Nitrogen was used as carrier gas for the GC, and helium for the GC-mass spectrometer (MS). One $\mu \mathrm{l}$ of the headspace volatile collection was injected onto the column. A fast program was used: $40^{\circ} \mathrm{C}$ (initial time) for 2 min., ramp: $10^{\circ} \mathrm{C} / \mathrm{min}$, final time $220^{\circ} \mathrm{C}$ for $5 \mathrm{~min}$. The GC outlet was split into two. One portion was sent to a flame ionization detector (FID), whereas another portion was led into the air stream over the mosquito head. $\mathrm{GC}$-traces and antennal responses were visualized on a computer monitor. Co-occurring FID peaks and antennal responses were identified using a HP 5970 GC-MS fitted with a solgelwax column (Agilent). Chirality of the compounds was verified by injecting the sample and standards in a HP-chiral column.

\section{Electro-antennogram recordings}

For electro-antennogram (EAG) recordings, we used unfed, mated, 5-10 day-old female mosquitoes. A pipette tip with half a mosquito's head including the antennae protruding was vertically mounted under an Olympus microscope at $400 \times$ magnification. Glass capillaries with a silver wire were filled with Beadle-Ephrussi ringer solution [19]. The recording glass electrode was placed at the tip of the flagellum, and the reference electrode was inserted through the eye. The EAG signal was preamplified $10 \times$ using a Syntech probe (Syntech, 
Kirchzarten, Germany). A Syntech I/O box combined signals from different channels (EAG, stimulus, GC-trigger and GC). After A/D conversion (Syntech IDAC PCI card), the signals were visualized and saved on a PC with Syntech software.

\section{Landing assays}

Thirty to thirty-five Ae. aegypti females (5-10 days old) were released into the landing assay cage $\left(26 \pm 1^{\circ} \mathrm{C}\right.$ and $65 \pm 5 \% \mathrm{RH}) 3$ hours prior to the experiments, without access to sugar solution. Landing assays were performed in a $30 \mathrm{~cm}$ cubic gauze cage (BugDorm, MegaView, Taiwan), with one side replaced by a Plexiglas panel with two holes through which landing tubes could be inserted. Landing tubes were standard test tubes, diameter $25 \mathrm{~mm}$, length $150 \mathrm{~mm}$, which were sandblasted to improve odour adhesion. The tubes were heated by two metal rods at $40^{\circ} \mathrm{C}$ inserted into the glass tubes at the start of the experiment. Two landing tubes were rubbed through the experimenter's palms for 2 minutes. The tubes were exchanged between the two hands every 15 seconds. Ninety $\mu \mathrm{l}$ of a test odour (see below) was spread onto one tube using a micropipette, and hexane was similarly applied on the control tube. The tubes were inserted through the holes in the cage and the number of mosquitoes landing on the tubes was scored every 30 seconds during the ensuing 90 seconds. In between each experiment with a test odour, a control test was carried out with two tubes with only human odour rubbings. The tube holders were wiped with ethanol after each experiment. The time between two consecutive trials was 15 minutes. Mosquitoes were used for a maximum of eight consecutive trials. The sequence of odours offered on the tubes was randomized. Generally between $60-80 \%$ of the mosquitoes landed on the tubes, but if fewer than $50 \%$ of the mosquitoes responded (measured between each trial as a control test), the test was terminated and a new batch of mosquitoes was used.

The following odours were tested (purity, CAS number and company from which they were purchased): linalool (+/-, > 97\%, CAS 78-70-6, Aldrich); 1-octen-3-ol (> 98\% purity, CAS 3391-86-4, Aldrich); trans-caryophyllene (> 98.5, CAS 87-44-5, Aldrich); naphthalene (> 99\%, CAS 91-20-3, Fluka); methyl salicylate (> 98\%, CAS 119-36-8, Aldrich); (-)- $\alpha$-copaene (> 96\%, CAS 3856-25-5, Sigma); methyl cinnamate (> 99\%, CAS 10326-4, Fluka); ocimene (E:Z:allo-, 28:62:3, CAS 13877-913, International Flavors and Fragrances). Odours were diluted in decadic steps in hexane.

\section{Statistical analysis}

Counts of landings over time in treatment tests and control test were summed over 90 seconds and fit to a logit function using treatment and test number as factors. The significance of factors in the contribution to the model was statistically tested using a $\mathrm{X}^{2}$ distribution.

\section{Results and Discussion \\ Headspace composition of 0 . forskolei}

In this study we tested whether GC-EAD analyses can be used to identify repellent compounds from headspace extracts of repellent plants. We found that a number of compounds in $O$. forskolei extracts elicited consistent electrophysiological responses in antennae of Ae. aegypti (Figure 1). Eight candidate compounds were identified through GC-MS analyses and selected for further landing bioassays, including (S)-(-)-linalool, naphthalene, methyl salicylate, (S)-(+)-1-octen-3-ol, (R)-(-)- $\alpha$-copaene, (E)-ocimene, methyl cinnamate and trans-caryophyllene.

The compounds that we identified in this study are found in a number of other Ocimum species in varying ratios. Kéita et al. [20] investigated three Ocimum spp., and found that the essential oil of $O$. basilicum was dominated by around $70 \%$ linalool, whereas O. gratissimum and O. suave had little or no linalool, but the former around 1\% alpha-caryophyllene and the latter around 1\% beta-caryophyllene. Jirovetz et al. [21] also found $O$ basilicum essential oil to be characterised by linalool (30\%), though less than $1 \%$ was found in $O$. americanum, O. gratissimum and O. sanctum. Methyl cinnamate was dominant in O. americanum and $O$. basilicum, but not detected in O. gratissimum and $O$. sanctum, beta-caryophyllene made up $16 \%$ of the essential oil of the latter. Kasali et al. [22] found that O. basilicum contained $10.8 \%$ linalool and 6.3\% (Z)-methyl cinnamate. Analysis of the essential oils from twelve varieties of basil (Ocimum spp.) found that ten of them were characterized by a high percentage of methyl cinnamate, ranging from $35 \%$ to $80 \%$ [23]. Of the other two, one was characterised by a high concentration of linalool and the other by a high concentration of caryophyllene.

\section{O. forskolei volatiles suppress landing of Ae. aegypti}

We subsequently tested which of the volatile compounds identified in the headspace collection of $O$. forskolei reduced landing in bioassays with Ae. aegypti. Most compounds did not show evidence of mosquito repellency at any of the concentrations tested $\left(10^{-3}\right.$ to $\left.10^{-5}\right)$. These include 1-octen-3-ol, (E)-ocimene, naphthalene, caryopyllene and $\alpha$-copaene. In contrast, the oxygenated monoterpene linalool, and the benzenoids methyl cinnamate and methyl salicylate did reduce landing at a concentration of $10^{-3}\left(\mathrm{X}^{2} \mathrm{DF}=5, \mathrm{P}<0.001, \mathrm{P}\right.$ $<0.001$, and $P=0.012$, resp. Figure 2). No significant effects of test number on repulsion were recorded. The model using treatment and day as factors sufficiently 


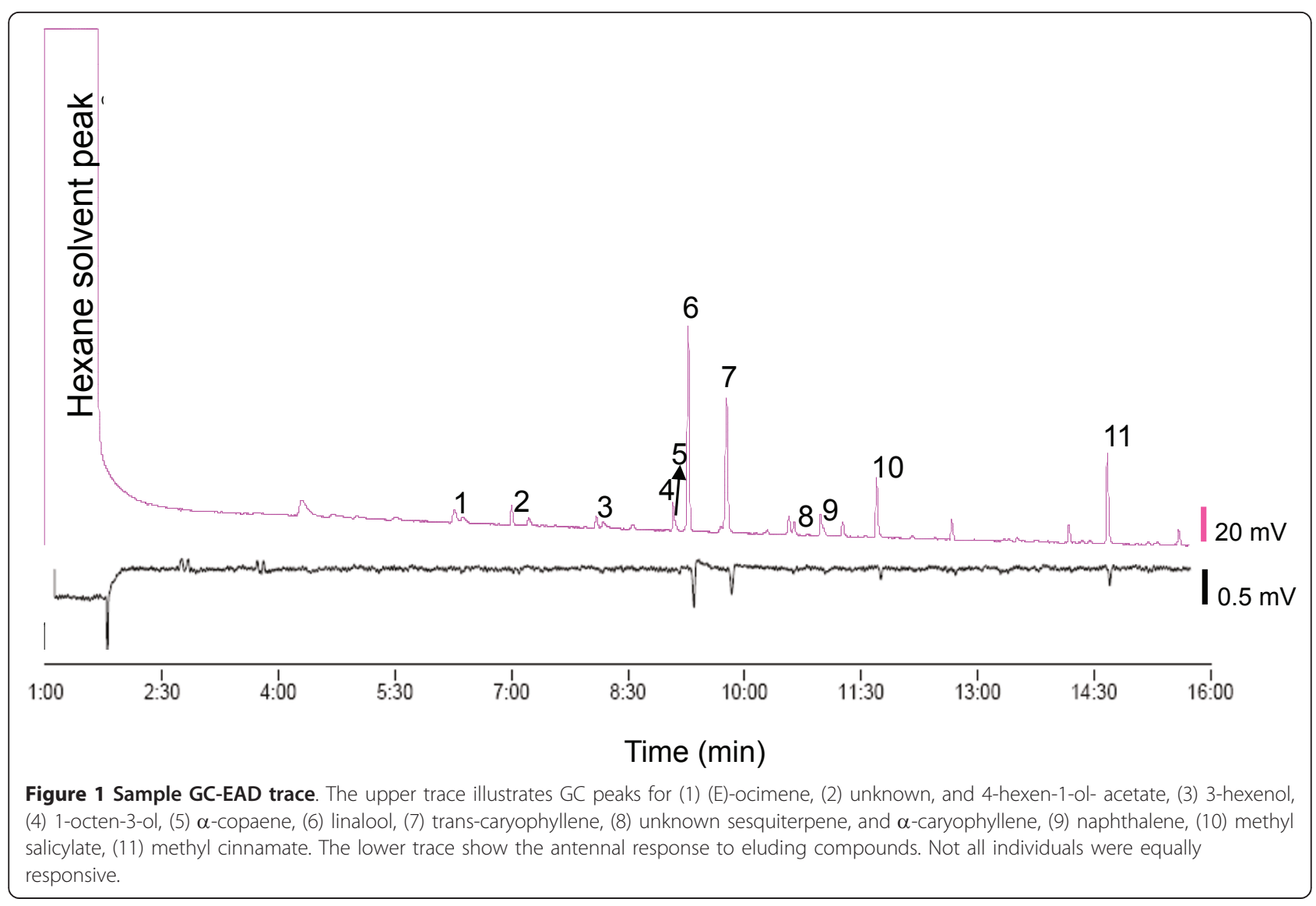

explained the variance in all comparisons (Pearson's Goodness-of-Fit, P > 0.1 in all cases). Lower concentrations of these compounds did not reduce landing rates compared to the control. Control experiments interspersed by actual tests (white bars in Figure 2) demonstrate that the choice of mosquitoes between the two baited glass rods was symmetrical, i.e., there was no bias for either side of the cage (Figure 2, white bars).

Our results indicate that the mosquito repellent activity of O. forskolei is based on at least three compounds. The compounds, linalool, methyl salicylate and methyl cinnamate all repelled Ae. aegypti by $40-70 \%$ at $10^{-3}$ in a simple landing bioassay. Linalool and methyl cinnamate are commonly reported components of essential oils, and Ocimum spp. have been reported to contain varying quantities of these compounds [e.g. [21-23]]. Linalool [24] and caryophyllene [13] are recognised as mosquito repellents, although the latter did not repel mosquitoes in our landing assays. However, methyl cinnamate and methyl salicylate have not previously been described as mosquito repellents. The potential of $O$. forskolei for use against a range of mosquito species is increased by the presence of a number of structurally unrelated active compounds. In the present study, activity was found against Ae. aegypti. However, O. forskolei was also repellent for Anopheles arabiensis in the field [14] and An. stephensi under laboratory conditions [18], indicating similar mechanisms of detection, processing and mode of repulsion by these compounds across mosquito genera. The results also demonstrate that electroantennographic detection in combination with landing assays can be used to identify potential repellents, and may indicate a mode of action through activation of olfactory receptor neurons. The technique may thus be used in the identification of repellent compounds from other plants with mosquito repellent properties.

Inasmuch as the compounds identified here are found in most Ocimum spp., so are the repellent properties generic across this genus. O. forskolei reduced biting by over $50 \%$ against $A n$. arabiensis under field conditions [14], and reduced capture of An. stephensi in a dual choice olfactometer under laboratory conditions [18]. Fresh O. canum is used as a mosquito repellent in native villages in Guinea Bissau in West Africa, and in field tests had a repellency of over 60\% [25]. Fresh plant material of $O$. americanum has been used as a mosquito repellent in Kenya [9,10], whereas O. suave and O. kilimandscharium are used extensively in Tanzania, and are highly effective in bioassays against a range of mosquito species [15]. In addition, there are reports of Ocimum 


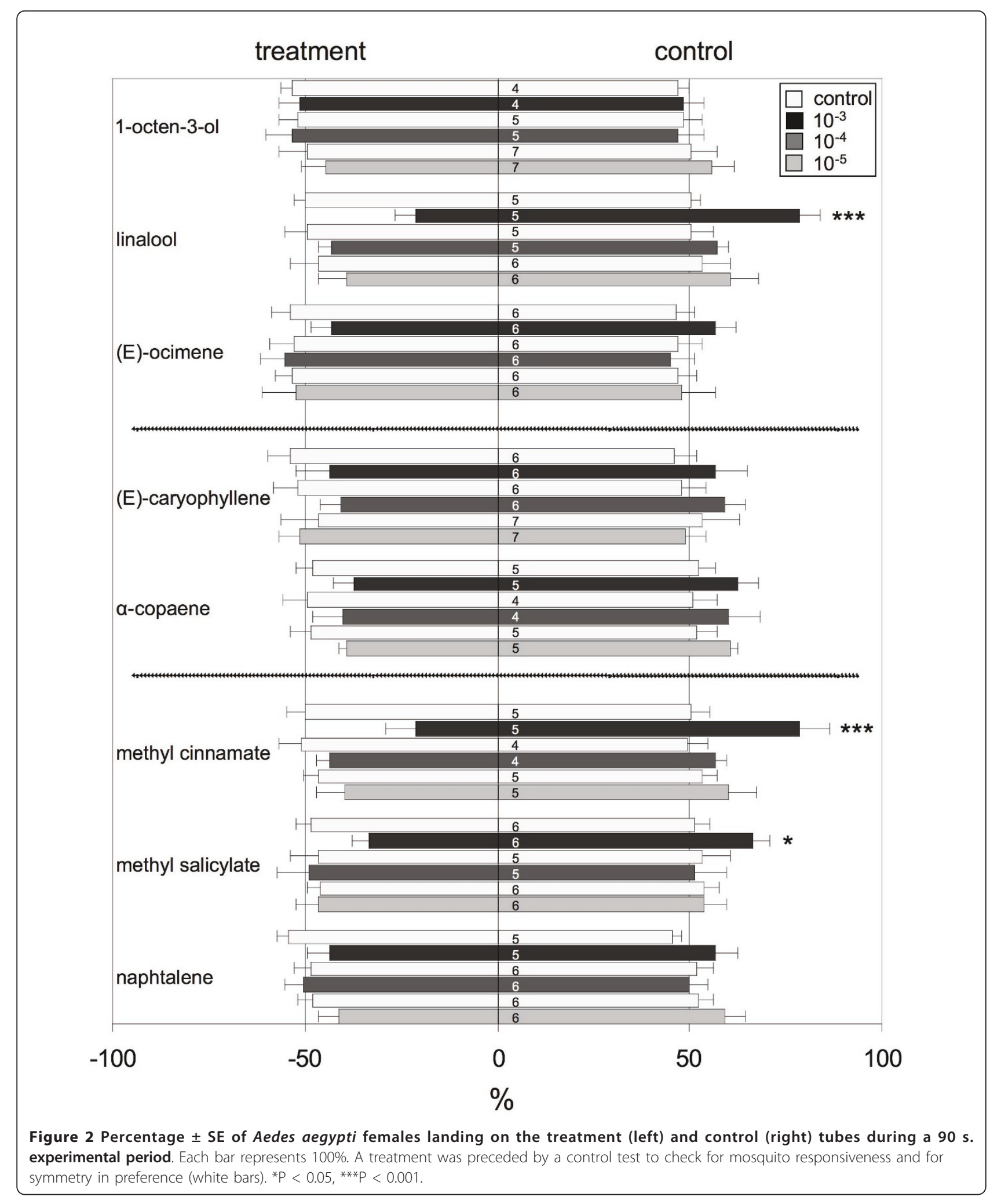


spp. being used as mosquito repellents via burning or thermal expulsion [e.g. $[10,11,26]]$, or through the use of essential oils [e.g. $[12,13,26]]$. Given such a wide range of source material, Ocimum spp. merit a systematic investigation of their relative properties. Ocimum species differ considerably in their volatile constituents, which could imply that a combination of various species or their synthetic mimics may further augment the repellency of Ocimum species.

\section{Use of mosquito repellent plants and their compounds in mosquito control}

Whereas synthetic repellents such as DEET can reduce biting to an extent that can be sufficient to suppress outbreaks of malaria in South Africa [5], there are issues of cost, logistics and toxicity [e.g. [6]], and in some cases of resistance $[27,28]$. In contrast, native plants have the advantages of low cost and local availability. In addition, Ocimum spp. exert their effect at a distance rather than at close range or upon contact, which minimizes the risk of toxicity. However, low toxicity of topical Ocimum selloi oil [13] indicates that Ocimum spp. may also be suitable as topical repellents.

The use of native plants may be a locally sustainable piece in the puzzle of establishing integrated mosquito vector control. Whilst insecticide treated bed nets provide excellent protection during sleep, repellents protect prior to bedtime. Repellents may especially be effective against opportunistic or zoophilic mosquitoes, which can be diverted to an alternative host. The repellent activity reported here for O. forskolei is clearly only a small part of the potential available within Ocimum spp. Selection and combination of different strains or Ocimum species may further improve their potential. Their low cost means that they can benefit even the poorest members of a community. This alone makes improving the understanding of such systems a worthy goal.

\section{Conclusions}

This study demonstrates that $O$. forskolei is repellent for a range of mosquito species. Active compounds identified through GC-EAD and GC-MS include R-(-)-linalool, methyl salicylate and methyl cinnamate. The results indicate that repellents can be identified through measuring summed olfactory responses (EAG), which may indicate that these repellents function through activating olfactory receptor neurons. Methyl salicylate and methyl cinnamate are newly described mosquito repellents. Identification of a diverse set of repellent compounds helps in the identification of their mode(s) of action and opens up possibilities for creating superior repellents through combination.

\section{Acknowledgements}

We thank the technical staff at the Division of Chemical Ecology and Department of Entomology for their work in maintaining insect and plant material. Funding for Maedot Waka from International Science Projects at Uppsala University is gratefully acknowledged, as is the contribution to this project of the late Prof Chris Curtis of LSHTM.

\section{Author details}

${ }^{1}$ Division of Chemical Ecology, Department of Crop Science, Swedish University of Agricultural Sciences PO 44, Alnarp, SE-23053 Sweden. ${ }^{2}$ Department of Biology, University of Asmara, Asmara, Eritrea. ${ }^{3}$ Department of Ecology, Swedish University of Agricultural Sciences, Box 7044, Uppsala SE-750 07, Sweden.

\section{Authors' contributions}

All authors were involved in the design of the experiments. TD, MW and RG carried out the experiments and analysed the data. TD and RH wrote the first draft of the manuscript. All authors approved the final version of the manuscript.

\section{Competing interests}

The authors declare that they have no competing interests.

Received: 16 May 2011 Accepted: 22 September 2011

Published: 22 September 2011

\section{References}

1. Takken W, Knols BGJ: Odor-mediated behavior of Afrotropical malaria mosquitoes. Ann Rev Entomol 1999, 44:131-157.

2. Hemingway J, Beaty BJ, Rowland M, Scott TW, Sharp BL: The Innovative Vector Control Consortium: improved control of mosquito-borne diseases. TRENDS Parasitol 2008, 22:308-312.

3. Pates H, Curtis C: Mosquito behavior and vector control. Ann Rev Entomol 2005, 50:53-70.

4. Nerio LS, Olivero-Verbel J, Stashenko E: Repellent activity of essential oils: A review. Bioresource Technology 2010, 101:372-378.

5. Durrheim DN, Govere JM: Malaria outbreak control in an African village by community application of 'deet' mosquito repellent to ankles and feet. Med Vet Entomol 2002, 16:112-115.

6. Nentwig G: Use of repellents as prophylactic agents. Parasitology Research 2003, 90:S40-S48.

7. Curtis CF, Lines JD, Baolin L, Renz A: Natural and synthetic repellents. In Appropriate Technology in Vector Control. Edited by: Curtis CF. Florida: CRC Press; 1990:75-92.

8. Ansari MA, Razdan RK: Operational feasibility of malaria control by burning Neem oil in Kerosene lamp in Beel Akbarpur village, District ghaziabad. Indian J Malariol 1996, 33:81-87.

9. Seyoum A, Kabiru EW, Lwande W, Killeen GF, Hassanali A, Knols BGJ: Repellency of live potted plants against Anopheles gambiae from human baits in semi-field experimental huts. Am J Trop Med Hyg 2002, 67:191-195.

10. Seyoum A, Killeen GF, Kabiru EW, Knols BGJ, Hassanali A: Field efficacy of thermally expelled or live potted repellent plants against African malaria vectors in western Kenya. Trop Med Int Health 2003, 8:1005-1011.

11. White GB: The insect-repellent value of Ocimum spp. (Labiatae): traditional anti-mosquito plants. East African Med J 1973, 50:248-252.

12. Gbolade AA, Oyedele AO, Sosan MB, Adewoyin FB, Soyelu OL: Mosquito repellent activities of essential oils from two Nigerian Ocimum species. J Trop Med Plants 2000, 1:146-148.

13. de Paula JP, Gomes-Carneiro MR, Paumgartten FJR: Chemical composition, toxicity and mosquito repellency of Ocimum selloi oil. J Ethnopharmacol 2003, 88:253-260.

14. Waka M, Hopkins RJ, Curtis C: Ethno-botanical survey and testing of mosquito repellent plants traditionally used in Eritrea. J Ethnopharmocol 2004, 95:95-101.

15. Kweka EJ, Mosha FW, Lowassa A, Mahande A, Mahande MJ, Massenga CP, Tenu F, Lyatuu EE, Mboya MA, Temu EA: Longitudinal evaluation of Ocimum and other plants effects on the feeding behavioural response of mosquitoes (Diptera: Culicidae) in the field in Tanzania. Parasites and Vectors 1:42. 
16. Aisen MSO, Imasuen AA, Wagbatsoma VA, Ayinde BA: Preliminary evaluation of the repellent activity of some plant essential oils against Simulium damnosum s. I., the vector of human onchocerciasis. Int I Trop Ins Sci 2004, 24:196-199.

17. Mwangi EN, Hassanali A, Essuman S, Myandat E, Moreka L, Kimondo M: Repellent and acaricidal properties of Ocimum suave against Rhipicephalus appendiculatus ticks. Exp Appl Acarol 1995, , 19: 11-18.

18. Waka M, Hopkins RJ, Glinwood R, Curtis C: The effect of repellents Ocimum forskolei and deet on the response of Anopheles stephensi to host odours. Med Vet Entomol 2006, 20:373-376.

19. Bjostad LB: Electrophysiological methods. In Methods in Chemical Ecology Chemical Methods. Edited by: Millar JG, Haynes F. Netherlands: Kluwer Academic Publishing, Dordrecht; 1998:339-375.

20. Kéita SM, Vincent C, Schnit J-P, Bélanger A: Essential oil composition of Ocimum basilicum L., O. gratissimum L. and O. suave L. in the Republic of Guinea. Flavour Frag J 2000, 15:339-341.

21. Kasali AA, Eshilokun AO, Adeola S, Winterhalter P, Knapp H, Bonnlander B, Koenig WA: Volatile oil composition of new chemotype of Ocimum basilicum L. from Nigeria. Flavour Frag J 2005, 20:45-47.

22. Vina A, Murillo E: Essential oil composition from twelve varieties of basil (Ocimum spp) grown in Colomia. J Brazilian Chem Soc 2003, 14:744-749.

23. Jirovetz L, Buchbauer G, Shafi MP, Kaniampady MM: Chemotaxonomical analysis of the essential oil aroma compounds of four different Ocimum species from southern India. Eur Food Res Techn 2003, 217:120-124.

24. Park BS, Choi WS, Kim JH, Lee SE: Monoterpenes from thyme (Thymus vulgaris) as potential mosquito repellents. J Am Mosq Ctrl Assoc 2005, 21:80-83.

25. Pålssson $\mathrm{K}$, Jaenson TGT: Plant products used as mosquito repellents in Guinea Bissau, West Africa. Acta Tropica 1999, 72:39-52.

26. Tawatsin A, Wratten SD, Scott RR, Thavara U, Techadamrongsin Y: Repellency of volatile oils from plants against three mosquito vectors. $J$ Vector Ecol 2001, 26:76-82.

27. Klun JA, Strickman D, Rowton E, Williams J, Kramer M, Roberts D, Debboun M: Comparative resistance of Anopheles albimanus and Aedes aegypti to N, N-Diethyl-3-methylbenzamide (Deet) and 2Methylpiperidinyl-3-cyclohexen-1-carboxamide (Al3-37220) in laboratory human-volunteer repellent assays. J Med Entomol 2004, 41:418-422.

28. Stanczyk M, Brookfield JFY, Ignell R, Logan JG, Field LM: Behavioral insensitivity to DEET in Aedes aegypti is genetically determined trait residing in sensillum function. Proc Natl Acad Sci USA 2010, 107:8575-8580

doi:10.1186/1756-3305-4-183

Cite this article as: Dekker et al.: Identification of mosquito repellent odours from Ocimum forskolei. Parasites \& Vectors 2011 4:183.

\section{Submit your next manuscript to BioMed Central and take full advantage of:}

- Convenient online submission

- Thorough peer review

- No space constraints or color figure charges

- Immediate publication on acceptance

- Inclusion in PubMed, CAS, Scopus and Google Scholar

- Research which is freely available for redistribution

Submit your manuscript at www.biomedcentral.com/submit
Biomed Central 